\title{
Ethical care and use of animals for educational purposes: A challenge for science teachers
}

\author{
Rian de Villiers \\ University of Pretoria, South Africa \\ Rian.deVilliers@up.ac.za
}

\begin{abstract}
The care and use of animals in education and medical research are very controversial and emotional public issues. Society needs to discuss these issues to reach an ethical stand. A sample of 118 sciences student teachers from a South African university responded to a questionnaire on animal rights and using animals for food, clothes, sport, entertainment, and specifically education and medical research. The responses were analysed qualitatively and/or quantitatively. The results indicated that students generally care for an animal's life. Students responded positively (with conditions) concerning the use of animals for education and medical research. They considered animals as a necessity for food and education. They were not in favour of using animals for sport and entertainment. The results showed that the animals' hierarchy of classification influenced the responses of the students and that more students are in favour of dissection rather than vivisection. Female student teachers are more averse to dissection and vivisection than males. The implications of the findings for teaching of subjects in the life sciences at educational institutions are considered. A number of suggestions are made regarding the use of animals for teaching purposes.
\end{abstract}

Keywords: life sciences teachers, applied animal use, animal rights, student teacher attitudes

\section{Introduction}

Parakh and Slesnick (1989) highlight that since the scientific revolution started about 500 years ago, the call for use of animals in scientific research and education has been continually increasing. These authors point towards the fact that research with animals makes vital contributions to a range of human life enhancing therapies, and it advances scientific understanding. This same research can cause pain and distress for the animals involved and may result in their death. Many people feel that animals do not necessarily feel pain the same way as humans do. Rollin (2006) points out that some people may feel that animal research is simply wrong, regardless of the crucial roles it plays in the quality of human life and that of pet animals, while others may feel that the morality of animal research depends on the achievements and objectives, whether it is carried out humanely, and what the consequences might be if it were not carried out at all. The English philosopher Jeremy Bentham (1748-1832), famously asked, "The question is not, Can they reason? nor, Can they talk? but, Can they suffer?" (Guerrini, 2003, p. 3). In this regard, the use of animals in various economical, educational and research areas is both controversial and emotional, and debate related to animal values is particularly found in life sciences (biology), veterinary sciences, zoology, physiology and anatomy classes. Topics like animal rights and the use and care of animals, especially in research and education, tend to challenge the deepest emotions of researchers, academics, learners ${ }^{1}$, students ${ }^{2}$ and the general public. Animal use refers to the use of animals for food, clothing, entertainment and as research 
and teaching subjects. Accepting the doctrine of animal rights means no hunting, no experiments on animals, no breeding and killing of animals for food, clothes or medicine, no use of animals for hard labour and in entertainment (Regan, 1983; Polkinghorne, 2005).

In some countries, particularly in the United States and Europe (see Capaldo, 2004; Donaldson \& Downie, 2007; Foster, Stannistreet \& Boyes 1994; Millet \& Lock, 1992; Stannistreet, Spofforth \& Williams, 1993), some controversial questions regarding animal care and use have long been debated. Millet and Lock (1992) examined secondary schools learners' attitudes towards the use of animals in schools. Thirty-eight percent indicated that they would object to any animal material being used for dissection. The study of Stannistreet et al. (1993) showed that 48\% of secondary school learners thought that animal dissection was wrong. On examining 13-14 year old learners' attitudes towards the use of animals in education and research, Foster et al. (1994) revealed that only $26 \%$ of the learners found animal dissection for teaching acceptable. The learners' views about animal experimentation for research depended on the purpose of the research. Capaldo's (2004) study indicated that students were opposing the use of invasive procedures on animals. Donaldson and Downie (2007) reported a study wherein university-level students were questioned on their attitudes to animal uses in higher education. These students recognised the educational value of animal uses, while disapproving of killing animals for this purpose. However, in developing countries such as those in Southern Africa, the debate on animal care and use is new to the public domain. De Villiers and Sommerville (2005) studied prospective life sciences teachers' attitudes towards animal dissection. The study revealed that more than two-thirds (70\%) of the students had positive attitudes with regard to animal dissection, and that females were more averse to dissection than male learners. However, this study was limited to students' attitudes to dissection only. It identified a need for a survey of wider ethical views of student teachers. In an attempt to ensure that science is used ethically, society needs to discuss these issues to reach ethical and practical solutions.

The care and use of animals can be a contentious issue, bringing about a discussion of animal rights. The use of animals, especially in research and education raises complex questions: Who has the right to determine animal rights? Do animals have the right to freedom from cruelty? Is it wrong to bother about animal rights when there is so much human suffering in the world? Is there any difference between animal rights and human rights? The proponents of animal rights claim that there are some practices that are morally wrong. Animals possess not only moral standing equal to that of human beings, but also basic moral rights that match those of humans (Horsthemke, 2010). 'Animal rights' principles hold that using animals is wrong; they should be protected from being exploited for human purposes (Würbel, 2009). According to Hopkins (2008), animals have no rights under South African law. This is also true for most industrialised countries.

Within the animal rights movement, educators, scientists, philosophers, lawyers, and other thinkers have struggled to decide what kinds of rights animals might have and what the source of these rights could be. Herzog (1990) reviewed two prominent philosophical approaches to animal rights. These two approaches, the utilitarian and non-consequentialist (right-based) approach are used to frame the research reported on in this paper. From opposite theoretical camps, Peter Singer, a utilitarian, and Tom Regan, a non-consequentialist, have worked out the seminal moral theories concerning the ethical treatment of animals (Rowe, 2009). Singer (1975), author of the provocative book Animal Liberation, argues that all animals have the capacity to suffer and, therefore, are the subject to equal moral consideration. He explains that at least some creatures have certain fundamental rights, such as the right not to be harmed and the right to moral 
consideration. He also labels prejudice in favour of humankind as 'speciesism'. Utilitarians acknowledge that animals have rights, but they justify animal research by its outcome. In other words, the pain and death of animals used in research is outweighed by the research-related reduction in disease, death and suffering of humans and other related animals species. On the other hand, non-consequentialists assert that the use of animals for research is morally wrong because animals should have the same rights as humans. The non-consequentialistic argument is argued by Regan (1983) in The Case for Animal Rights. He argues that animals are 'subjects-oflife', and as such are bearers of rights. He further argues that, because the moral rights of humans are based on their possession of certain cognitive abilities, and because these abilities are also possessed by some animals, such animals must have the same moral rights as humans. Singer is primarily concerned with improving the treatment of animals and accepts that individual animals might be used legitimately to further human or non-human ends, while Regan believes we ought to treat animals as we would human beings. Both Regan and Singer believe that devoting practical and conceptual energies to an ethic for animals is "not a matter of care or sympathy; it is a matter of justice" (Rowe, 2009, p157). The question arises: which of the two approaches are acceptable for prospective life- and natural sciences teachers?

Despite the fact that the attitudes of people with regard to the use of animals could form barriers to effective learning, little is known about prospective South African science teachers' attitudes and the implications these might have. The National Curriculum Statement, Life Sciences (2003) raises learners' and students' awareness of the existence of different viewpoints in a society, and encourages open-mindedness towards perspectives that are based on scientific knowledge, values, ethics, beliefs, attitudes and biases. However, the consequences of these requirements for training the teaching corps are a major concern, particularly since most teachers are unfamiliar with the approaches needed to develop the necessary skills of argumentation and debate in their learners. The purpose of the study is to examine the views of pre-service science teachers toward animal rights and the applied use and ethical care of animals by humans. This study sought these students' attitudes on the use of animals for food, clothes, sport, entertainment, and specifically education and medical research. Besides reporting the findings in regard to the attitudes of these prospective science teachers, I will discuss the implications of these attitudes with regard to the teaching of life sciences and disciplines of life sciences. Although multi-cultural classes were involved in this preliminary study, the main focus of this paper is to present an exploration of prospective science teachers' views toward animal rights and the care and use of animals.

\section{Objectives of the study}

Based on the above rationale, the following research questions were addressed in the study:

- What are the opinions of pre-service science teachers toward animal rights?

- Does gender and culture influence these opinions?

- To what extent do these pre-service teachers approve the applied uses of animals?

- What are the implications of pre-service teachers' attitudes in regard to the teaching of life sciences?

\section{Research methodology}

Sample and participants: A purposive sampling method was used. A sample of 118 Bachelor of Education (BEd), pre-service life sciences and general sciences teachers at a single, urban 
university in South Africa participated in this preliminary study. Only students enrolled for the courses zoology or the learning area science were involved in this empirical study. Pre-service natural sciences teachers were included because a life sciences component is part of the learning area science curriculum.

Instrument: The questionnaire was approved by the Faculty Research Ethical Committee. The questionnaire (written in English) contained both open-ended and closed questions, and was completed voluntarily during routine classes. The responses yielded demographic data as well as information on students' personal experiences of, attitudes and opinions toward animal rights. The demographic items had bearing on gender, age, year of study, religion, culture group and area of specialisation. The attitudinal items on the questionnaire consisted of 57 statements in total, divided into sections that dealt with human beings versus animals (Section A, 33 statements), animals in medical research (Section B, 10 statements) and animals in education (Section C, 10 statements). Items of the questionnaire allowed for views of both supporters and opposers of animal rights. Many of these statements were obtained from Wasted Lives (Animal Aid Education Department, 2001). In each case the students were required to tick one of four options on a Likert scale for 53 statements to indicate to which extent they agreed or disagreed with each statement: $(1=$ strongly agree, $2=$ agree, $3=$ disagree, $4=$ strongly disagree $)$. An additional four statements (Section $\mathrm{C}$ ) tested the degree of acceptability $(1$ = acceptable, $2=$ conditionally acceptable, $3=$ not acceptable) in the opinion of the students. All the statements (closed questions) appeared in a list. Open-ended questions were included in a 'general section' as well as in sections $\mathrm{A}$ and $\mathrm{C}$.

Data analysis procedure: The responses to the open-ended questions were analysed both qualitatively and quantitatively. The responses to the closed questions were analysed only quantitatively. These Likert responses were reduced to two: agree ('strongly agree' and 'agree' combined) and disagree ('strongly disagree' and 'disagree' combined). Negatively worded statements were reversed scored to be aligned with the 'positive' statements. Statistical analysis (summary statistics and two-way tables) of the survey data was used to elaborate and enhance the discussion. The Chi-squared test was used to test for association with gender. Fisher's Exact test was used to test for association with culture because the 2-way contingency tables were sparse with some expected frequencies less than 5, which makes Chi-squared inappropriate. Only answers to some of the questions and statements are reported here. Results are presented as percentages rounded to whole numbers. Sample sizes of some items were too small for meaningful analysis.

Validity and reliability: The questionnaire's content validity was face-validated by two experts in the field of life sciences, who are competent to judge whether the questionnaire reflects the content domain of the study. The questionnaire was pilot-tested with ten students enrolled in the third year of the zoology course. Based on the feedback from the pilot study and the experts, the questionnaire was revised. Redundancies and ambiguities were removed to improve the clarity in the formulation of certain items in the questionnaire. The reliability of the questionnaire responses was acceptable with a Cronbach's alpha coefficient (Cohen, Manion \& Morrison, 2007) of 0.78 .

\section{Results}

\section{Biographical information}

Hundred and fifty five questionnaires were handed out and $118(76 \%)$ were returned. Of these 96 $(81 \%)$ were zoology students and the other $22(19 \%)$ were learning area science students. The 
students' ages ranged between 18 and 27 years $($ mean $=19)$. The majority of students $(66 \%)$ were female. Regarding religious background, 93\% were Christian, 2\% were Muslim and 5\% indicated their religion as 'other'. The majority (66\%) were 'African' (Ndebele, Northern Sotho, Southern Sotho, Swazi, Tsonga, Tswana, Xhosa and Zulu), 26\% were Afrikaans, 7\% English and $1 \%$ Indian.

\section{Human beings versus animal rights}

From the results, it appears that students generally respect an animal's life. In response to the question "Are you for or against animal rights?" 94\% of the students indicated that they were in favour (responding either 'for' or 'strongly for') of animal rights. Slightly more students with a 'Western' culture background (95\%) than 'African' students (93\%) were for animal rights. More females (96\%) than males (89\%) believed that animals have rights. The students' positive responses to the open-ended, follow-up question "Motivate your answer" were classified into seven categories (Table 1). All these categories elicited from students' comments in support of animal rights are a clear indication that they accept the utilitarian view of animal rights. The main reason for students' positive responses (31\%), involved the "comparison with human beings" category. Their responses correlate with Singer's (1975) utilitarian view that when we as humans weigh the consequences of an act in order to judge whether it is right or wrong, the interests of animals ought to be given equal consideration to the similar interests of human beings. Utilitarians judge the rightness of an act by its consequences, and by the extent to which it satisfies the preference of those affected, minimizing pain and suffering and maximizing pleasure.

Table 1: Students' reasons for supporting animal rights

\begin{tabular}{|l|c|}
\hline \multicolumn{1}{|c|}{$\begin{array}{c}\text { Categories elicited from students' comments } \\
\text { in support of animal rights }\end{array}$} & $\begin{array}{c}\text { Percentages } \\
\text { (\%) }\end{array}$ \\
\hline Comparison with human beings & 31 \\
Should be treated with respect & 20 \\
Pain/feelings/emotions & 14 \\
Abuse/cruel/inhumane & 13 \\
Created by God & 8 \\
Conservation/protection & 8 \\
Can't speak & 6 \\
\hline
\end{tabular}

Participants were asked to comment on the following question: "In nature, animals kill and eat each other. Is it right for humans to kill and eat animals?" Their responses were classified as right (78\%), wrong (21\%) or uncertain (1\%). Most students were in favour of using animals for food (see also Table 3).

Typical positive responses provided by students were:

"Animals are part of the food chain"; "To keep balance in an ecosystem - survival of the fittest"; "According to the Bible, we can kill and eat animals"; "Animals may be killed as long as it is done humanely"; "In some South African cultures it is tradition for certain kind of live animals to be slaughtered during weddings and funerals". 
The following comments reflect some students' negative reactions:

"Animals also have feelings"; "The animals might be endangered and end up extinct"; "If you kill them which means you disrespect their rights"; "They have a right to live"; "Humans can live without eating animals".

Table 2 below shows students' statements concerning animal rights in terms of percentages of positive or negative responses. The results show that most students held the view (either 'agree' or 'strongly agree') that animals should have the right to live natural lives (96\%) and that we (humans) should treat animals with compassion and respect (96\%) as we would wish to be treated (88\%). The respondents disagree (either 'disagree' or 'strongly disagree') that animals must suffer for human advancement and gain (92\%), humans have the right to use animals as they wish $(92 \%)$ and it is wrong to bother about animal rights when there is so much human suffering in the world (83\%).

Table 2: Student responses for items related to animal rights

\begin{tabular}{|c|c|c|c|c|}
\hline \multirow{2}{*}{ Statement } & \multicolumn{4}{|c|}{ Responses (\%) } \\
\hline & SA & A & D & SD \\
\hline \multicolumn{5}{|l|}{ Positive responses } \\
\hline Animals should have the right to live natural lives & $\underline{65}$ & $\underline{31}$ & 3 & 1 \\
\hline We should treat all animals with compassion and respect & $\underline{64}$ & $\underline{32}$ & 3 & 1 \\
\hline We should treat animals as we would wish to be treated & $\underline{58}$ & $\underline{30}$ & 10 & 2 \\
\hline $\begin{array}{l}\text { Animals that humans use have a happier life since they } \\
\text { are fed and protected }\end{array}$ & $\overline{21}$ & $\underline{45}$ & $\underline{24}$ & 10 \\
\hline The export of live animals for slaughter is uncivilized & 26 & $\underline{38}$ & $\underline{27}$ & $\underline{9}$ \\
\hline \multicolumn{5}{|l|}{ Negative responses } \\
\hline Animals must suffer for human advancement and gain & 3 & $\underline{5}$ & $\underline{36}$ & $\underline{56}$ \\
\hline $\begin{array}{l}\text { Humans are the pinnacle of evolution and that gives } \\
\text { them the right to use animals as they wish }\end{array}$ & 4 & $\underline{4}$ & $\underline{37}$ & $\underline{55}$ \\
\hline It is wrong to bother about animal rights when there is & & & & \\
\hline so much suffering in the world & 3 & $\underline{14}$ & $\underline{44}$ & $\underline{39}$ \\
\hline Humans have the right to confine an animal & 6 & $\underline{37}$ & $\underline{37}$ & 20 \\
\hline It demeans humans to give rights to animals & 8 & $\underline{28}$ & $\underline{35}$ & $\underline{29}$ \\
\hline
\end{tabular}

$\mathrm{SA}=$ Strongly agree, $\mathrm{A}=$ Agree, $\mathrm{D}=$ Disagree, $\mathrm{SD}=$ Strongly disagree

\section{The applied use of animals}

The students responded positively (either 'agree' or 'strongly agree') concerning the use of live animals for education, medical research, food, clothing and sport (Table 3). More students were in favour of the use of animals for educational purposes $(83 \%)$ than medical research (66\%). The highest percentage (92\%) students found it acceptable to use live animals for food while more than half $(53 \%)$ responded positively for using animals for clothing. Some students were not in favour (responded either 'disagree' or 'strongly disagree') to using animals for sport and entertainment (Table 3). Over half of the students were against using live animals for sport (53\%) and entertainment (55\%). The results indicated small differences (e.g. 24-27\%) in responses to the extent in which the students responded to the use of animals for sport. More males than females found it acceptable to use live animals for food, clothing, medical research, education, 
sport and entertainment. The analysis provided statistical evidence of a significant association between the students' gender and their responses to the 'clothing' statement $(p=0.0078)$. Of the students, $70 \%$ males and $44 \%$ females found it acceptable to use live animals for clothing. Both the 'African' and 'Western' students were against using live animals for sport (e.g. 55\% and $79 \%$ ) and entertainment (e.g. 59\% and 71\% respectively). The analysis provided statistical evidence of a significant association between the students' culture and their responses to the 'medical research' statement in table $3(\mathrm{p}=0.0374)$.

Table 3: Responses of students concerning the applied use of live animals

\begin{tabular}{|c|c|c|c|c|}
\hline \multirow{2}{*}{ Usage } & \multicolumn{4}{|c|}{ Responses (\%) } \\
\hline & SA & A & D & SD \\
\hline Food & 44 & 48 & 2 & 6 \\
\hline Education & $\overline{34}$ & $\overline{50}$ & 8 & 8 \\
\hline Medical research & $\underline{24}$ & $\underline{42}$ & 15 & 19 \\
\hline Clothing & 19 & 34 & 24 & 23 \\
\hline Entertainment & $\overline{14}$ & $\overline{31}$ & 20 & $\underline{35}$ \\
\hline Sport & 24 & 23 & $\underline{26}$ & $\overline{27}$ \\
\hline
\end{tabular}

$\mathrm{SA}=$ Strongly agree, $\mathrm{A}=$ Agree, $\mathrm{D}=$ Disagree, $\mathrm{SD}=$ Strongly disagree

\section{The killing of animals for educational purposes}

Concerning the use of animals for educational purposes, students responded positively in regard to killing insects (63\%), reptiles (57\%), fish (57\%), amphibians (57\%) and birds (51\%). However, more than half (56\%) rejected the killing of any mammals. The percentage of negative responses for using mammals in education and research are similar (all 56\%). The majority of the 'African' students found it acceptable to kill reptiles (69\%), fish (66\%), amphibians (63\%), and birds (60\%) for educational purposes. The 'Western' students were less in favour of killing animals. They found it not acceptable to kill birds (71\%), mammals (68\%), reptiles (68\%), fish (63\%) and amphibians (55\%). Both 'African' (66\%) and 'Western' (58\%) students found it acceptable to kill insects for educational purposes. Both males (76\%) and females (57\%) prefer to kill insects rather than mammals, birds, reptiles, fish and amphibians.

The majority of students (88\%) considered using caged animals for the education of learners as very important. They were of the opinion that it teaches the learners how to care for and treat $(21 \%)$ and how to respect $(16 \%)$ animals; and that it also teaches learners about biodiversity (15\%), dangerous animals (14\%), life processes (14\%) and ethological data (8\%). Most students indicated that live animals should be studied in secondary schools $(58 \%)$ and tertiary institutions (79\%) but not in nursery schools (51\%) and primary schools (56\%). Negative responses included:

"The children in nursery and primary schools are too young and may be traumatized"

"Animals are made to live in their own natural environment, where they belong"

"There is no guarantee that the animals will be looked after in a school environment"

"Animals sometimes have unpredictable behaviour"

"Visits to the zoo will be more beneficial to study live animals" 


\section{Dissection versus vivisection in education and research}

Table 4 gives the responses to the statements relating to the use of animals for teaching and medical research. In general, the results showed that students prefer doing dissections on dead animals rather than vivisection (experimentation with live animals). A number of students (54\%) found it acceptable to dissect dead animals, followed by dissection of animal organs (41\%), and doing experiments with live animals $(26 \%)$.

\section{Dissection}

The Likert scale analysis suggested that a student's culture group and gender could influence the responses to the dissection statements. The first statement concerned the dissection of animal organs in teaching. The analysis provided statistical evidence of a relationship between the students' culture and their responses to statement 2 . The analysis provided no statistical evidence of a relationship between the students' gender and their responses to statements 1 and 2. More males $(45 \%)$ than females $(39 \%)$ found dissection of animal organs acceptable $(\mathrm{p}=0.6156)$. Of the students, $41 \%$ (37\% 'Western' and 42\% 'African') indicated that they thought this was acceptable $(\mathrm{p}=0.3230)$. Half $(50 \%)$, gave responses in the "conditionally acceptable" category, the main condition being that the animals had died naturally. The responses to the second statement, which concerned dissection of dead animals in teaching showed that more than half of the students (54\%) found it acceptable. Three-quarters (75\%) of the students with an 'African' cultural background and 38\% students with a 'Western' cultural background found dissection of dead animals in teaching acceptable $(\mathrm{p}=0.0055)$. One-third $(33 \%)$ found it 'conditionally acceptable'. The main condition was, as with the previous statement, that the animal died from natural causes. Once again, more males $(63 \%)$ than females $(49 \%)$ found dissection of dead animals more acceptable $(\mathrm{p}=0.1437)$. The 'conditionally acceptable' responses of the students were relatively high, i.e. $50 \%$ (statement 1 ) and 33\% (statement 2) respectively. The main 'conditionally acceptable' reasons for not dissecting animals and animal organs in teaching were:

Dissection of animal organs in teaching

"Don't kill animals specifically for their organs, use animals which are already dead"

"If the animal was slaughtered for food the organs may assist greatly in learning instead of being thrown away"

"It is okay, but the animal must have died from natural causes"

\section{Dissection of dead animals in teaching}

"Depending on the way it was killed"

"It's against animal rights"

"As long as we don't specifically kill the animal for dissection purposes"

"Only if the animal died naturally"

\section{Vivisection}

The Likert scale analysis suggested that a student's culture group and gender could influence the responses to the vivisection statements. More students are in favour of dissection rather than vivisection. The third and fourth statements on the questionnaire probed students' views about vivisection (experiments with live animals) in teaching and medical research. Comparison of the attitudes to vivisection for different purposes showed that students were more against vivisection in an educational context (41\%) than in a medical research context $(35 \%)$. The analysis 
provided statistical evidence of a relationship between the students' culture and their responses to statements 3 and 4. No statistical evidence emerged of a relationship between the students' gender and their responses to statements 3 and 4 although more females (47\%) as compared to males $(30 \%)$ found vivisection in teaching unacceptable $(\mathrm{p}=0.1437)$. More 'Western' students $(58 \%)$ than 'African' students $(32 \%)$ were against vivisection in teaching $(\mathrm{p}=0.0136)$. More than three-quarters of the males $(76 \%)$ than females $(61 \%)$ were positive about vivisection in medical research $(\mathrm{p}=0.3554)$. A quarter of the 'African' students $(25 \%)$ and $55 \%$ of the 'Western' students were against vivisection in medical research $(\mathrm{p}=0.0109)$. A relatively high percentage gave responses indicating that they found vivisection in teaching (33\%) and medical research (30\%), 'conditionally acceptable'. The main 'conditionally acceptable' reasons for not using animals in experiments were:

Experiments with live animals in teaching

"As long as the animals don't get hurt"

"Depending on the type of experiment done"

"It depends on the learning outcomes of the lesson"

"Depending on the size and type of animal"

Experiments with live animals in medical research

"It is vital that boundaries are set"

"Some animals have not much value to earth"

"It depends on the importance of the research"

"Only if the animals are not harmed"

Table 4: Student responses to items concerning the use of animals for teaching and research

\begin{tabular}{|l|c|c|c|}
\hline \multicolumn{1}{|c|}{ Procedure } & $\begin{array}{c}\text { Acceptable } \\
\text { (\%) }\end{array}$ & $\begin{array}{c}\text { Conditionally } \\
\text { acceptable } \\
\text { (\%) }\end{array}$ & $\begin{array}{c}\text { Not } \\
\text { acceptable } \\
\text { (\%) }\end{array}$ \\
\hline $\begin{array}{l}\text { 1. Dissection of animal organs in teaching } \\
\text { 2. Dissection of dead animals in teaching } \\
\text { 3. Experiments with live animals in } \\
\text { teaching }\end{array}$ & 41 & 50 & 9 \\
$\begin{array}{l}\text { 4. Experiments with live animals in } \\
\text { medical research }\end{array}$ & 26 & 33 & 41 \\
\hline
\end{tabular}

\section{Teaching 'animal rights' at tertiary level}

Teaching about animal rights is probably one of the most effective ways of opening student's minds to the nature of animals. Almost three quarters (73\%) of the respondents would like an animal rights course to be included in zoology, life sciences and general sciences at tertiary level. One student commented: "Teachers in training must know that every life is precious and that every living organism has rights". Lecturers, who are teaching animal rights, have to get the students to think critically and not foster their own agenda. They should be encouraged to explore animal-human relations, argue for and against alternative courses of action, examine the values held by society and question information from all sides in the animal rights debate. 
With regard to teaching animal rights, the participants ranked seven teaching methods according to preference. They reported videos as an effective practical teaching method because it is an excellent way to introduce the topic of animal rights and form a good foundation for lessons development. They also considered the visual images of videos as realistic and capable of maintaining people's interest. Videos were followed in order of preference by class debates, discussions, lectures, group work, printed matter, and questions and answers. It is recommended that lecturers use mixed methods - one possibility would be presenting a lecture and then a video followed by a class debate. Debates generate ideas and heated involvement.

\section{Discussion}

\section{Limitations of the study}

Seeing that some of the demographic groups in this research were too small for testing statistically significant relationships (e.g. for religious groups), the focus of the analysis fell on larger groups (e.g. gender and culture). Despite these limitations, the information gleaned from the small number of participants in this study can be used to raise issues and possibly initiate some debate in term of animal rights and the challenges facing educators when using animals in education.

\section{Implications and challenges for the teaching of life sciences and related disci- plines}

Concerns about issues associated with the use of animals in education and research may lead to classroom discussions, disputes and debates. Globally, more and more secondary and tertiary educational institutions face various challenges and problems when some learners and students object to dissection, vivisection and other practices. Lecturers need to be equipped for a debate on these issues, and aware that a sizeable proportion of their students might doubt the appropriateness of the use of animals or organs in their classes. Lecturers in the life sciences need to understand their students' concerns and feelings about using animals (dead or alive) in the classroom. We have to instill in learners and students a respect towards nature. Horsthemke (2009, p. 1) argued that "we need to teach not as if nature mattered but that it matters". Because most of the students attracted to life sciences are the very people who are attracted to and love animals, it is not surprising that these issues may present real conflicts for them at this stage in their careers. The study of Capaldo (2004) showed that when students are forced to use animals in ways that they view as stressful, harmful or painful to animals, the following reactions may occur: students' cognitive abilities may become impaired, resulting in less learning; they may suffer psychological trauma; and they may lose interest in science when not given the option to object. Lecturers have to seek ways to meet students' intellectual, moral and emotional needs. It is important that lecturers are sympathetic and aware of attitudes and opinions, which their students might hold, about animal rights. Students with scientific, moral and ethical objections to dissection or vivisection have a right not to be discriminated against because of their compassion and respect for life. It is important to be neutral regarding discussions of animal rights in the classroom. Lecturers may not exclude from a course students who are strongly concerned about animal rights. They have to re-examine the morality and instructional effectiveness of exclusion. However, lecturers may find it very difficult to accommodate all these things in an acceptable manner.

Educators should place greater emphasis on the place of ethics and ethical thinking within the life sciences by encouraging students to recognise the existence of disparate views, to understand 
them by engaging discussion (De Lange, 2005). Cultural progressivists have argued that humane education in schools is needed to cause a major shift from viewing animals as 'them' to viewing them as part of 'us' (Horsthemke, 2009). Pecore, Demetrikopoulos \& Frantz (2007) designed a lesson plan for teachers which can be used in a non-teaching, constructivist approach to challenge students to examine scientific ethics regarding animal care and use. The challenge for educators is to present information about animal care and use that enables students and learners to contemplate what people considers ethical and lawful, and why. The suggest using Yager's, (1991) constructive learning cycle with four main components: engage learners and students in the topic by considering everyday encounters between humans and other organisms; explore existing ideas about codes of conduct in general and animal use in particular; explain guidelines about animal care and use; and take action by considering sample case studies. According to Nyika (2009) and the South African National Standard (2008) efforts should always be made to uphold the principles of the three R's which stipulate that researchers and educators should replace animals with other alternatives whenever possible, and if not possible then the number of animals used should be reduced to the minimum possible sample and refine the methodologies in order to minimize any harm that may be caused by experimental procedures. Morrison (2003), on the other hand, described five ethical principles guarding the use of animals in research.

The students' responses to the attitudes statements have important implications for those teaching the pedagogic of the life sciences. If the lecturer is a proponent of animal use as an effective instructional tool, he/she has to acquaint him/herself with the religious concerns of all students in a multicultural society. It must be kept in mind that all the large religions are present in South Africa. Some religions do not support the killing of certain types of animals, or any animals, for unnecessary purposes. On the other hand, if the lecturer is an opponent of animal use, the intellectual needs of some students may be oppressed. The students' attitudes may impinge on the subject- matter the lecturer is teaching and produce a resistance to, or distraction from effective learning. Another crucial issue is that we as educators do little to prepare our learners and students to overcome many scientific ethical obstacles they may encounter in their occupations. A bioethics component should be included in all anatomy, physiology, life sciences, natural sciences and zoology courses. Being informed about scientific ethics is critical, not only for learners and students but for all members of society. All citizens will occasionally make bioethical decisions as a result of today's biotechnology revolution.

Mechanisms, and especially in schools in South Africa should be put in place to ensure that all use of animals is in compliance with the principles of the South African National Standard (2008). The clause, "The use of animals to demonstrate knowledge or techniques in scientific disciplines in schools and tertiary institutions" in this document (p 61), refers to three important general principles. Firstly, all teaching activities which involve the use of animals shall have approval by an Animal Ethics Committee which is satisfied that there is no suitable alternative to the use of animals, and that the number of animals involved and the impact on them is minimized. Secondly, animals should be used for teaching activities only when there are no suitable alternatives for achieving the educational objectives. Thirdly, students shall be given the opportunity to discuss the ethical, social and scientific issues that are involved in the use of animals for scientific studies and teaching activities.

South Africa is at the beginning of an entirely new chapter in the history of animal rights. The applied uses of animals, and especially dissection and vivisection are not likely to disappear in the near future. The opinions about the use of animals in education and medical research are critical for reaching decisions in the broader context of ethical and social values. Based on the 
statistics presented above it appears that most students feel that animals have rights and that they accept the utilitarian view of animal rights. The anti-vivisectionists and anti-dissectionists are asking for teachers and educational institutions to recognize that animals are sentient beings and that we have a duty to represent them as something other than disposable instructional tools. On the other hand, it makes sense for vivisectors and dissectors to have first-hand experience of what one is teaching and as in the case of veterinarians and physicians, dissection and vivisection could be classified as vocationally necessary for life- and natural sciences teachers. Where do we as life sciences educators draw the line?. Students have the right to learn and lecturers have the right to properly teach, but at the same time animals have the right to live.

\section{Endnotes}

1 Learners: a term used in South Africa to indicate persons educated in schools

2 Students: a term used in South Africa to indicate persons educated in tertiary institutions

\section{Acknowledgements}

The author wishes to thank Jaqui Sommerville in the Department of Statistics at the University of Pretoria for her constructive comments and stimulating feedback.

\section{References}

Animal Aid Education Department. (2001). Wasted Lives. Canterbury: Animal Aid Education Department.

Capaldo, T. (2004). The psychological effects on students of using animals in ways that they see as ethically, morally or religiously wrong. Atla-alternatives to laboratory animals, 32, 525-531.

Cohen, L., Manion, L., \& Morrison, K. (2007). Research Methods in Education. London and New York: Routledge.

De Lange, M.C. (2005). Integrating philosophical and bio-ethical perspectives in life sciences facilitator education. South African Journal of Higher Education, 19, 1062-1073.

Department of Education. (2003). National Curriculum Statement Grades 10-12 (General) Life Sciences. Pretoria: Government Printer.

De Villiers, J.J.R., \& Sommerville, J. (2005). Prospective biology teachers' attitudes toward animal dissection: implications and recommendations for the teaching of biology. South African Journal of Education, 25(4), 247-252.

Donaldson, L., \& Downie, R. (2007). Attitudes to the uses of animals in higher education: has anything changed?. Bioscience Education. Retrieved April 14, 2010, from http://www.bioscience.heacademy. ac.uk/journal/vol10/beej-106.pdf

Foster, C. Stannisstreet, M., \& Boyes, E. (1994). Children's attitudes to the use of animals in education and research: what are their justifications and reservations? School Science Review, 76, 39-44.

Guerrini, A. (2003). Experimenting with humans and animals: from Galen to Animal rights. Baltimore, MD: Johns Hopkins University Press.

Herzog, H. A. (1990). Discussing animal rights and animal research in the classroom. Teaching of Psychology, 17, 90-94. 
Hopkins, K. (2008). A legal argument against vivisection. Retrieved August 24, 2010, from http://www. animalrightsafrica.org/VivisectionlegalArgument.php.

Horsthemke, K. (2009). Rethinking humane education. Ethics and Education, 4(2), 201-214.

Horsthemke, K. (2010). The moral status and rights of animals. Porcupine Press: Johannesburg.

Millet, K., \& Lock, R. (1992). GCSE students' attitudes towards animal use: some implications for biology/science teachers. Journal of Biological Education, 26, 204-208.

Morrison, A. R. (2003). Ethical principles: guiding the use of animals in research. The American Biology Teacher, 65, 105-108.

Nyika, A. (2009). Animal research ethics in Africa: an overview. Acta Tropica, 1125, 548-552.

Parakh, J. S., \& Slesnick, I. L. (1989). Difficult decisions: Animal rights. The Science Teacher, 56, 36-37.

Pecore, J. L., Demetrikopoulos, M. K., \& Frantz, K.J. (2007). Student-centered deliberations of ethical care and use of animals. The American Biology Teacher, 69(7), 416-420.

Pifer, L., Shimizu, K., \& Pifer, R. (1994). Public attitudes toward animal research: some international comparisons. Society and Animals, 2(2), 95-113.

Pifer, L. (1996). Exploring the gender gap in young adults' attitudes about animal research. Society and Animals, 4(1), 37-52.

Polkinghorne, J. (2005). Exploring reality: The intertwining of science and religion. New Haven, CT: Yale University Press.

Regan, T. (1983). The case for animal rights. Berkeley: University of California Press.

Rollin, B. (2006). The regulation of animal research and the emergence of animal ethics: a conceptual history. Theoretical Medicine and Bioethics, 27(4), 285-304.

Rowe, B.D. (2009). Animal rights and human growth: intellectual courage and extending the moral community. Philosophical Studies in Education, 40, 153-166.

Singer, P. (1975). Animal liberation. New York: Avon.

South African National Standard, (2008). The care and use of animals for scientific purposes. Pretoria: SABS Standards Division.

Stannistreet, M., Spofforth, N., \& Williams, T. (1993). Attitudes of children to the uses of animals. International Journal of Science Education, 15, 411-425.

Yager, R.E. (1991). The constructivist learning model. The Science Teacher, 58(6), 52-57.

Würbel, H. (2009). Ethology applied to animal ethics. Applied Animal Behaviour Science, 118, 118-127. 